\title{
openheart Cross-sectional assessment of haemostatic profile and hepatic dysfunction in Fontan patients
}

\author{
Joelle Julius Nicolaas Daems (D) , ${ }^{1}$ Chantal Attard, ${ }^{2}$ Suelyn Van Den Helm, ${ }^{2}$ \\ Johannes Breur, ${ }^{3}$ Yves D'Udekem, ${ }^{4}$ Karin du Plessis, ${ }^{5}$ Thomas G Wilson, ${ }^{4,6}$ \\ David Winlaw (D) , ${ }^{7,8}$ Thomas L Gentles, ${ }^{9}$ Paul Monagle, ${ }^{2,10}$ Vera Ignjatovic ${ }^{2}$
}

To cite: Daems JJN, Attard C, Van Den Helm S, et al. Crosssectional assessment of haemostatic profile and hepatic dysfunction in Fontan patients. Open Heart 2021;8:e01460. doi:10.1136/ openhrt-2020-001460

Received 23 September 2020 Revised 24 December 2020 Accepted 22 February 2021
Check for updates

(c) Author(s) (or their employer(s)) 2021. Re-use permitted under CC BY-NC. No commercial re-use. See rights and permissions. Published by BMJ.

For numbered affiliations see end of article.

Correspondence to Drs Joelle Julius Nicolaas Daems; j.j.n.daems@ amsterdamumc.nl

\section{ABSTRACT}

Background Fontan-associated liver disease is accompanied by a hypercoagulable state. While hepatic dysfunction in Fontan patients is common, its relationship with haemostatic changes and clinical outcomes in this patient population remains unclear.

Objective To correlate liver dysfunction and haemostatic profiles with clinical outcomes in the Fontan population. Patients/methods Patients were enrolled in a multicentre, cross-sectional study in Australia and New Zealand. Hepatic structure and function were assessed using serum-based calculations (Fibrotest and model for end-stage liver disease excluding international normalised ratio scores). Haemostatic profiles were assessed by Thrombin Generation. Platelet function was assessed via Platelet Factor 4 (PF4) and P-selectin (P-SEL). Clinical outcomes were obtained from the Australian and New Zealand Fontan Registry.

Results Seventy-three patients participated in the study (mean age $18.9 \pm 8.5$ years with a mean of $13.5 \pm 6.9$ years post-Fontan). The Endogenous Thrombin Potential (ETP) for patients who suffered thrombotic events (TE) (1366.4 $\pm 66.2 \mathrm{nM} / \mathrm{min}$ ) was higher compared with patients with major bleeding events $(1011.1 \pm 138.4 \mathrm{nM} /$ $\min )(p=0.03)$. Except for a negative correlation between Fibrotest-score and PF4 ( $p=0.045)$, PF4 and P-SEL concentrations did not correlate with markers of hepatic dysfunction or structural abnormality.

Conclusions Increased ETP is associated with TE during clinical follow-up after Fontan. This study reinforces that hepatic dysfunction may contribute to the derangement of coagulation factors, impacting the individual risk of haemostatic complications for the Fontan population.

\section{INTRODUCTION}

Since its first application in 1968, the Fontan procedure has undergone significant modifications and has greatly improved the prognosis of patients with single ventricular congenital heart disease. ${ }^{1-5}$ With the ageing Fontan population, clinicians are now presented with the challenge of managing the haemodynamic and haemostatic changes and the associated long-term complications that follow Fontan sequelae. ${ }^{6}$ The prevalence of

\section{Key questions}

What is already known about this subject?

- Congestive hepatopathy is a common complication of Fontan physiology. Fontan patients also suffer from increased bleeding and thrombotic complications. The effect of liver disease on haemostasis is a field of interest and recently advances in the understanding of the haemostatic system in liver disease have provided strong support for a tenuous equilibrium of haemostasis which can easily be tipped towards a more bleeding-like or thrombotic-like diathesis. Little research has been done to investigate the effect of congestive hepatopathy on the haemostasis of Fontan patients. There is little evidence available to guide anticoagulant therapy in Fontan patients and current therapy is based on the clinical assessment for anatomic and haemodynamic risk factors and expert opinion

What does this study add?

- This is the first large study within this population to investigate haemostatic profiles and to correlate these to hepatic dysfunction and clinical outcome. This study stresses the complexity of haemostasis in liver disease, especially in Fontan patients.

How might this impact on clinical practice?

- It might change the approach clinicians have to haemostasis in Fontan population. It also shows promise for thrombin generation to be used as modality to assess the haemostatic profile in Fontan patients and to aid in the stratification of anticoagulant therapy.

adverse events associated with these changes such as TE and bleeding events is increasing. The prevalence rate of thrombotic events (TE) has been reported to be as high as $33 \% .^{7}$ Currently, no modality is available to assess the risk of bleeding and TE and anticoagulant therapy is given based on clinical assessment for anatomic- and haemodynamic risk factors and expert opinion. ${ }^{25}$

Recently, a hypercoagulable state in Fontan patients was described and several 
prothrombotic mechanisms have been proposed. ${ }^{3}{ }^{6}$ Fontan physiology is prone to significant vascular remodelling contributing to overall cardiac dysfunction. ${ }^{8}$ Adding to that, the haemodynamic changes in Fontan physiology such as low cardiac output, decreased pulsatile pulmonary blood flow, arrhythmias and heart failure lead to increased central venous pressure which is up to three times higher compared with the pre-Fontan lower body venous pressure. ${ }^{13}$ Fontan-associated congestive hepatopathy $(\mathrm{CH})$ is a common complication of Fontan physiology and leads to histopathologic changes in the liver-tissue and is associated with a derangement in procoagulant and anticoagulant protein levels and activity. ${ }^{13}$

Decreased activity of coagulation factors and protein $\mathrm{S}$ has been observed in a representative Fontan population. While these patients have increased levels of liver-derived antithrombin and endothelium derived free tissue factor pathway inhibitor (TFPI), they have a paradoxically increased thrombin generation (TG). ${ }^{6}$ The increased TG might be explained by the increased platelet activation (higher levels of soluble P-selectin and serum soluble CD40 ligand) as well as endothelial damage (increased von Willebrand Factor). Fontan patients also have a slightly lower inhibition of thrombin formation as reflected by a decrease in protein $\mathrm{S}$, increase in thrombinactivated fibrinolysis inhibitor and plasminogen activator inhibitor-1 antigen concentration. These complex haemostatic disorders may not in the least case be caused by liver disease as is reflected by the enhanced platelet activation and endothelial damage, impaired fibrinolysis and heightened thrombin formation observed in this population. ${ }^{6-12}$

Recent advances in the understanding of the haemostatic system in liver disease have provided strong support for a tenuous equilibrium of haemostasis, which can easily be tipped towards a more bleeding-like or thromboticlike diathesis due to depletion of both procoagulant and anticoagulant factors, changes in factor activity, vascular changes, endothelial damage, platelet activation and changes in vascular flow. ${ }^{11}$

All elements of Virchow's triad are present in the Fontan population and while they have increased concentration of antithrombin and endothelium-derived free TFPI, this could explain why the net effect seems to tip their haemostatic balance towards a more prothrombotic phenotype. $^{69-12}$

Understanding the laboratory measures associated with bleeding- and TE in Fontan physiology might aid in stratifying these patients for early detection of haemostatic derangement and hence carries the potential to implement timely prevention or treatment strategies. The TG curve or Thrombogram is an established tool to assess global coagulable state, as it reflects the overall function of the blood clotting system and its inhibitors. ${ }^{13-16}$ TG in platelet-poor plasma (PPP) makes it possible to investigate the net effect of changes in procoagulant and anticoagulant factors. ${ }^{14}$
This prospective cohort study set out to investigate the relationship between clinical outcome and haemostatic profiles and hepatic dysfunction in Fontan patients. The specific study aims were to:

Correlate TG to bleeding and TE; correlate plasmabased markers of platelet activity to bleeding and TE; and correlate liver dysfunction to TG, platelet activity parameters and bleeding and TE.

We hypothesised that: (1) Hepatic dysfunction in Fontan patients leads to significant changes in both procoagulant and anticoagulant factors which results in a more thrombotic phenotype as measured by TG; (2) The combination of both liver dysfunction and increased platelet activation leads to more TE in this population.

\section{METHODS \\ Design}

Cross-sectional observational study.

\section{Patients}

Suitable study subjects for the Fontan Liver Renal study were recruited by using the Australian and New Zealand Fontan Registry, the full design and administration of which has been described previously. ${ }^{17}$ All 152 included patients in the Fontan Liver Renal study were eligible for inclusion. The Fontan Liver Renal study collected data from three sites located in Melbourne (Victoria, Australia) and Sydney (New South Wales, Australia) and Auckland (New Zealand), as described elsewhere. ${ }^{18}$ Details regarding patient eligibility and inclusion and exclusion criteria are presented in figure 1.

\section{Patient and public involvement}

It was not appropriate to involve patients in the design, conduct and reporting of this study.

\section{Laboratory samples}

Laboratory tests for the New South Wales, Victorian and New Zealand participants were performed at the Children's Hospital at Westmead in Sydney, the Murdoch Children's Research Institute in Melbourne and the Starship Children's Hospital in Auckland respectively. All laboratory measurements were conducted on minimum 8-hour fasting venous blood samples. Age-dependent variables are presented as percentage of the upper limit of normal based on age and gender.

\section{Hepatic structure and function}

This study builds adopts the assessments of hepatic structure and function as reported in the Fontan Liver and Renal study. ${ }^{18}$ Additionally, the model for end-stage liver disease excluding international normalised ratio (MELDXI) scores was calculated by using bilirubin and creatinine by use of the following formula: MELD-XI=11.76 $($ loge creatinine $)+5.112($ loge total bilirubin $)+9.44 .^{19}$

\section{Haemostatic profile}

The coagulation profile was determined by TG and surrogate platelet activation markers. TG was measured 


\begin{tabular}{|l|}
\hline \multicolumn{1}{c|}{ Inclusion criteria: } \\
- Consent for participation in registry \\
sub-studies \\
- $\geq 8$ years old \\
$: \geq 5$ years post Fontan palliation \\
- Ability to attend study centre \\
\hline Sufficient plasma collected \\
\hline Exclusion criteria Fontan liver \\
renal study: \\
- Prior request not to be contacted \\
for study participation through the \\
Australian and New Zealand \\
Fontan Registry \\
- History of severe end-stage renal \\
impairment \\
- Pregnancy/breastfeeding \\
\hline
\end{tabular}

Figure 1 Flow chart of patient inclusion.

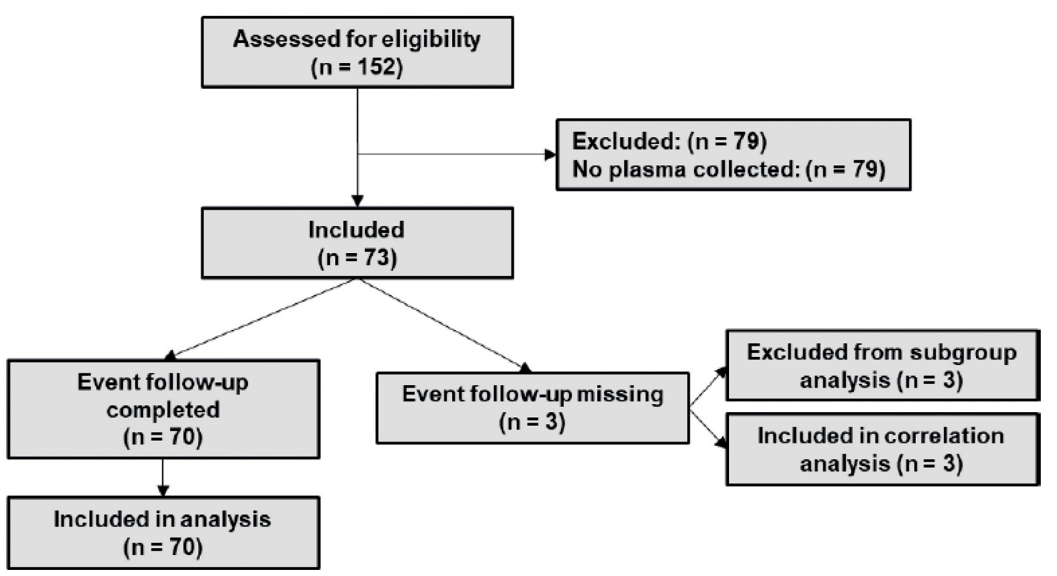

using the Calibrated Automated Thrombinoscope in PPP with 5pM PPP reagents and TG was performed in triplet to minimise intraexperiment variation. TG data are reported in endogenous thrombin potential (ETP), lag time, peak, time to peak, velocity index, start of tail and alpha 2 macroglobulin $(\alpha 2 \mathrm{M})$ level. Platelet activation was assessed by ELISA determination of platelet factor 4 (PF4 or CXCL4) and soluble P-selectin (sGPVI or CD62P). Plasma PF4 was measured using the abcam PF4 (CXCL4) human SimpleStep ELISA Kit. CD62P was measured using the R\&D Systems Human P-Selectin/ CD62P Immunoassay.

\section{Clinical outcome}

Primary outcome measures were defined as major bleeding, minor bleeding, bleeding and/or TE (table 1). Major bleeding events were defined by a modification of the definition published by the International Society on Thrombosis and Haemostasis. ${ }^{20}$ Medical history

\section{Table 1 Definition of major bleeding, minor bleeding and} thrombotic event

\begin{tabular}{|c|c|c|}
\hline Event & Classification & Definition \\
\hline \multirow[t]{5}{*}{ Bleeding } & Major bleeding & Fatal bleeding. \\
\hline & & $\begin{array}{l}\text { Symptomatic bleeding in a critical area } \\
\text { and/or organ. }\end{array}$ \\
\hline & & $\begin{array}{l}\text { Bleeding causing a fall in haemoglobin } \\
\text { level of } \geq 20 \mathrm{~g} / \mathrm{L} \text {. }\end{array}$ \\
\hline & & Bleeding leading to blood transfusion. \\
\hline & Minor bleeding & $\begin{array}{l}\text { Noted in patients' medical records but } \\
\text { did not meet major bleeding criteria. }\end{array}$ \\
\hline \multirow[t]{2}{*}{ Thrombotic } & & $\begin{array}{l}\text { Clinically objectified venous and/ } \\
\text { or arterial thromboembolic space- } \\
\text { occupying lesion within the lumen of the } \\
\text { cardiovascular system. }\end{array}$ \\
\hline & & $\begin{array}{l}\text { The occurrence of a clinical event } \\
\text { known to be highly associated with } \\
\text { a thrombotic event such as transient } \\
\text { ischemic attack, stroke, myocardial } \\
\text { infarction, and pulmonary embolism. }\end{array}$ \\
\hline
\end{tabular}

was investigated from the date samples were collected until august 2018. The average duration of follow-up is reported in table 2 .

\section{Analysis}

Data were analysed using IBM SPSS statistics V.25 (IBM). Values reported as being higher or lower than a certain value were analysed as that value for calculation purposes. Continuous variables (eg, all laboratory tests) are expressed as mean and SD or median and range, based on their distribution. Categorical variables (eg, bleeding and thrombosis) are expressed as number and percentage.

To investigate differences in nominal data, a $\chi^{2}$ test for goodness of fit was performed. To assess differences in thrombin-generation-related variables and outcomes between primary outcome groups, an independentsamples t-test was used. A Mann-Whitney $\mathrm{U}$ test was used if data was not normally distributed.

To investigate the relationship between measures of haemostasis and other variables correlation analysis was performed considering age, gender and other variables as possible confounders. A scatter plot was made to assess whether the relationship between variables appeared to be linear, if not a Kendall's $\tau$ b analysis was used to test correlation between variables. Trends over time were plotted and analysed for gradient of change.

It has been argued that while interpreting $p$ values, potentially medically important differences observed in small studies, for which the $\mathrm{p}$ value is more than 0.05 , are simply denoted as non-significant and ignored. Some subgroup analyses within this study are likely to be performed between small groups. To prevent loss of potentially important results $\mathrm{p}$ values between 0.05 and 0.10 are reported as trends.

\section{RESULTS}

\section{Patient characteristics}

A total of 73 patients were included in this study, figure 1. Patient characteristics and characteristics of the clinical event groups are presented in tables 2 and 3. Gender 


\begin{tabular}{|c|c|c|c|}
\hline \multirow{2}{*}{$\begin{array}{l}\text { Characteristics } \\
\text { Age in years, median (range), } \\
\text { mean (SD) }\end{array}$} & \multicolumn{2}{|l|}{ Participants $(n=73)$} & \multirow[t]{2}{*}{ P value } \\
\hline & $17.62(4.83-50.24)$ & $18.9-8.46$ & \\
\hline $\begin{array}{l}\text { Years post-Fontan, median } \\
\text { (range), mean (SD) }\end{array}$ & $12.93(0.33-30.13)$ & $13.52-6.98$ & \\
\hline $\begin{array}{l}\text { Duration of follow-up in years, } \\
\text { mean (SD) }\end{array}$ & & $3.72(0.61)$ & \\
\hline Pacemaker present, n (\%) & & $5(6.8 \%)$ & \\
\hline Male, $n(\%)$ & & $38(52.1 \%)$ & 0.725 \\
\hline \multirow[t]{2}{*}{ Site of inclusion, $\mathrm{n}(\%)$} & New South Wales & 49 (67.1\%) & $<0.030$ \\
\hline & Victoria & 24 (32.9\%) & \\
\hline \multirow[t]{11}{*}{ Diagnosis, n (\%) } & Aortic Atresia & $1(1.4 \%)$ & \\
\hline & CAVC & $9(12.3 \%)$ & \\
\hline & ccTGA & $8(11.0 \%)$ & \\
\hline & DILV & $17(23.3 \%)$ & \\
\hline & DORV & $6(8.2 \%)$ & \\
\hline & HLHS & $5(6.8 \%)$ & \\
\hline & Left-AV-valve-atresia & $1(1.4 \%)$ & \\
\hline & PA-IVS & $5(6.8 \%)$ & \\
\hline & PA-VSD & $2(2.7 \%)$ & \\
\hline & TA & $18(24.7 \%)$ & \\
\hline & VSD & $1(1.4 \%)$ & \\
\hline \multirow[t]{3}{*}{ Fontan type, $\mathrm{n}(\%)$} & AP & $9(12.3 \%)$ & $<0.001$ \\
\hline & ECC & $50(68.5 \%)$ & \\
\hline & LT & $14(19.2 \%)$ & \\
\hline \multirow[t]{4}{*}{ NYHA-classification, n (\%) } & Class 1 & $57(78.1 \%)$ & \\
\hline & Class 2 & $13(17.8 \%)$ & \\
\hline & Class 3 & $3(4.1 \%)$ & \\
\hline & Class 4 & $0(0 \%)$ & \\
\hline \multirow{5}{*}{$\begin{array}{l}\text { Liver panel as percentage of } \\
\text { upper limit, mean (SD) }\end{array}$} & Total bilirubin (\%) & $110.00(74)$ & \\
\hline & AST (\%) & $82.00(25)$ & \\
\hline & ALT $(\%)$ & $91.00(30)$ & \\
\hline & GGT (\%) & $117.00(71)$ & \\
\hline & $\operatorname{ALP}(\%)$ & $53.00(28)$ & \\
\hline \multirow{3}{*}{$\begin{array}{l}\text { Severity of liver disease, mean } \\
\text { (SD) }\end{array}$} & Fibro-scan & $17.53(1.04)$ & \\
\hline & Fibro-test score & $0.49(0.19)$ & \\
\hline & MELD-XI score & $3.78(4.85)$ & \\
\hline \multirow{5}{*}{ Events, $n(\%)$} & No events & 62 (84.93\%) & \\
\hline & Thrombotic events & $3(4.11 \%)$ & \\
\hline & Major bleeding events & $2(2.74 \%)$ & \\
\hline & Minor bleeding events & $3(4.11 \%)$ & \\
\hline & Missing & $3(4.11 \%)$ & \\
\hline
\end{tabular}

ALP, alkaline phosphatase; ALT, alanine aminotransferase; AP, atriopulmonary connection; AST, aspartate aminotransferase; AV, atrioventricular; CAVC, complete atrioventricular canal defect; ccTGA, congenitally corrected transposition of the great arteries; DILV, double inlet left ventricle; DORV, double outlet right ventricle; ECC, extracardiac conduit; GGT, gamma-glutamyl transferase; HLHS, hypoplastic left hear syndrome; LT, lateral tunnel; MELD-XI, model for end-stage liver disease excluding international normalised ratio; NYHA, New York Heart Association; PA-IVS, pulmonary atresia with intactventricular septum; PA-VSD, pulmonary atresia with ventricular septal defect; TA, tricuspid atresia; VSD, ventricular septal defect.

did not influence any of the study variables. Age had a weak positive correlation with lag time ( $\mathrm{tau}=0.204$, $\mathrm{p}=0.016)$, time to peak ( $\operatorname{tau}=0.274, \mathrm{p}=0.001)$ and start of tail (tau=0.266, $\mathrm{p}=0.001)$. A Mann-Whitney $\mathrm{U}$ test showed no significant difference in age between subgroups. The intracardiac total Cavo-pulmonary connection-Fontan type $(\mathrm{M}=2.59, \mathrm{SD}=4.72)$ has a significantly lower MELD-XI score when compared with the atriopulmonary connection $(\mathrm{M}=6.58, \mathrm{SD}=3.38, \mathrm{t}(57)=2.413, \mathrm{p}=0.019$, two tailed, $d=0.97$ ) and to the extracardiac total cavopulmonary connection-Fontan type $(\mathrm{M}=6.21, \mathrm{SD}=4.72$, $\mathrm{t}(62)=-2.54$, $\mathrm{p}=0.014$, two tailed, $d=-0.77)$. Other study variables did not differ between Fontan Types.

\section{Subgroup analysis}

Differences in TG, platelet activity markers and hepatic dysfunction between the no-events group and the different subgroups are presented in table 4 . The no-events group $(\mathrm{M}=156.20, \mathrm{SD}=61.32)$ has a significantly lower velocity index compared with the thrombotic group $(\mathrm{M}=178.33$, $\mathrm{SD}=10.58)$, $\mathrm{t}(-2.24)=12.68, \mathrm{p}=0.044$, two tailed, $\mathrm{d}=0.50$, $95 \%$ CI ( -43.57 to -0.69$]$. There were no significant differences in surrogate platelet activity between the no-events group and the different subgroups. When compared with the no-events group $(\mathrm{M}=3.31, \mathrm{SD}=4.68)$, the major bleeding group $(\mathrm{M}=10.1, \mathrm{SD}=4.74)$ has a significantly higher MELD-XI score, $\mathrm{t}(-2.00)=62, \mathrm{p}=0.0595 \%$ CI $(-13.47$ to -0.01$)$. The minor bleeding group $(\mathrm{M}=9.23$, $\mathrm{SD}=2.52$ ) also has a significantly higher MELD-XI score compared with the no events group, $\mathrm{t} \quad(-2.16)=63$, $\mathrm{p}=0.03495 \%$ CI $(-11.39$ to -0.45$)$. There were no statistically significant differences in Fibrotest-score between the no-events group and the different subgroups.

Differences in TG, platelet activity markers and hepatic dysfunction between the TE group and the major- and minor bleeding group are shown in table 5. The thrombotic group $(\mathrm{M}=1366.39, \mathrm{SD}=66.22)$ has significantly higher ETP than the major bleeding group $(\mathrm{M}=1011.06$, $\mathrm{SD}=138.44)$, t $(3)=4.03, \mathrm{p}=0.027$, two tailed, $d=3.27$ $95 \%$ CI (74.99 to 635.68). Comparison of the thrombotic group and the minor bleeding group $(M=1218.25$, $\mathrm{SD}=74.33$ ) showed a trend for a higher ETP in the thrombotic group, $\mathrm{p}=0.061$. The ETP distribution between subgroups is depicted in figure 2. There were no significant differences in surrogate platelet activity between the TE group and the major-bleeding and minor-bleeding group. The thrombotic group has a significantly lower MELD-XI score than the minor bleeding group, $t$ $(-4.48)=4, p=0.01195 \%$ CI $(-12.53$ to -2.95$)$. There were no statistically significant differences in Fibrotestscore between the TE group and the major-bleeding and minor-bleeding group.

Differences in TG, platelet activity markers and hepatic dysfunction between the major-bleeding and minorbleeding group are shown in table 6 . There were no statistically significant differences in TG, platelet activity or hepatic dysfunction between the major-bleeding and the minor-bleeding group. 


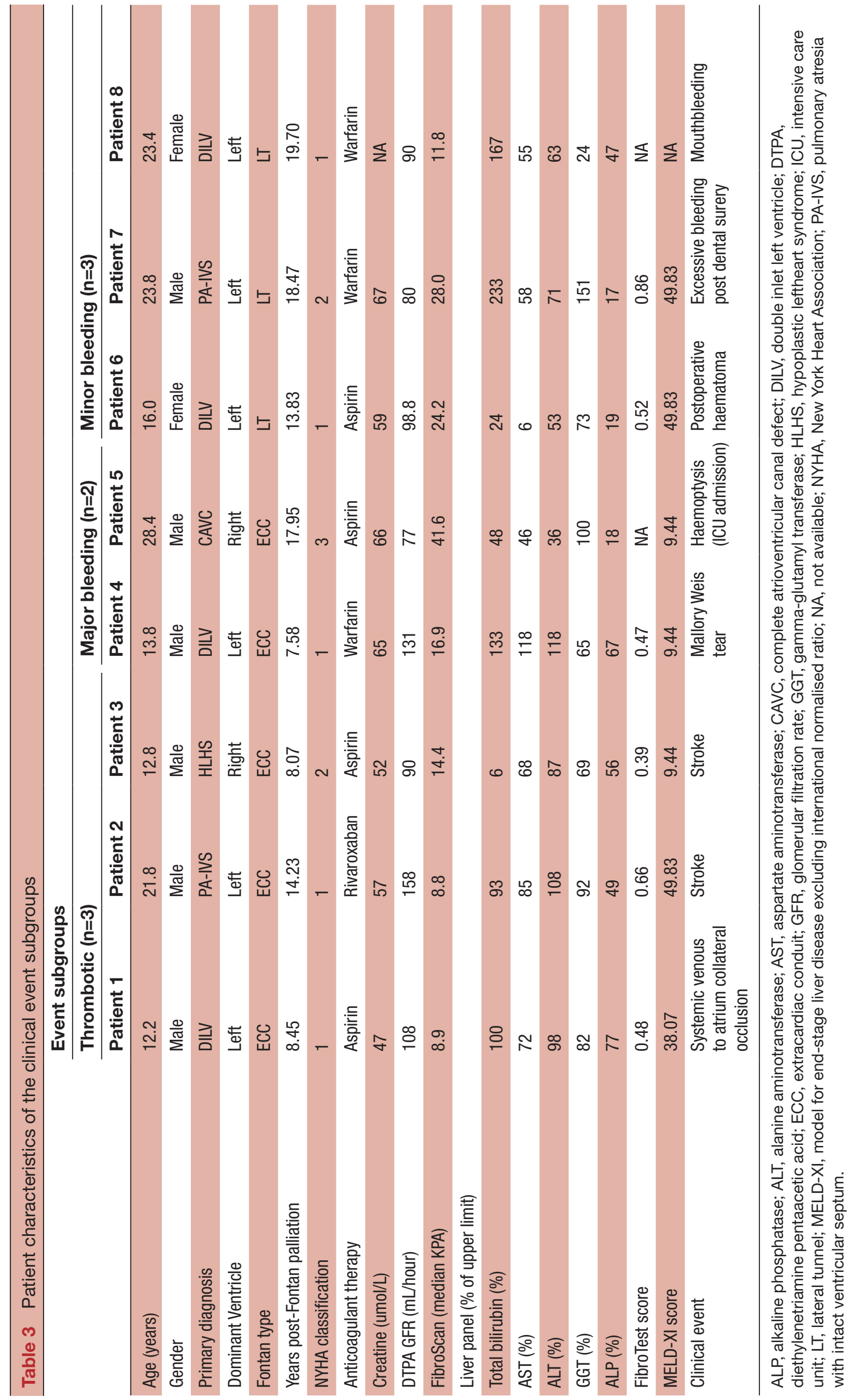




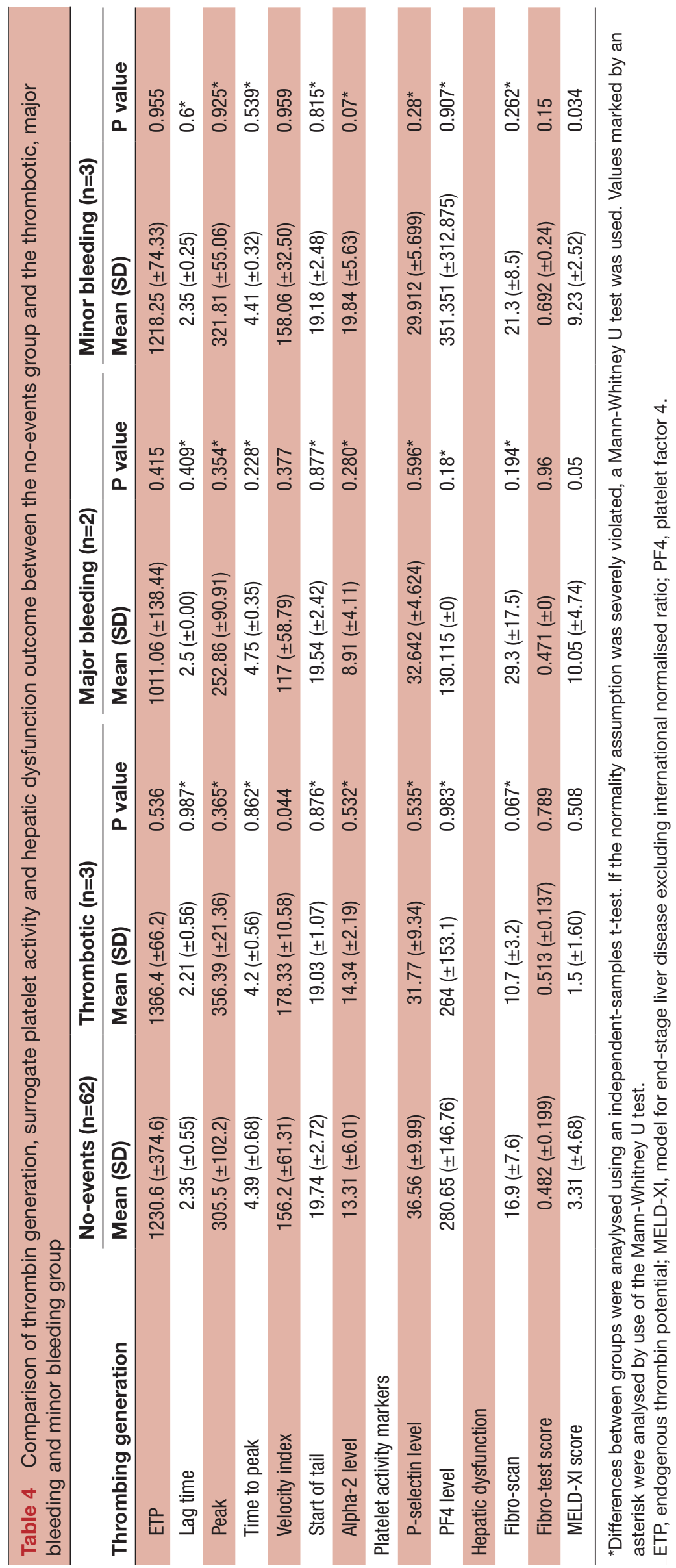




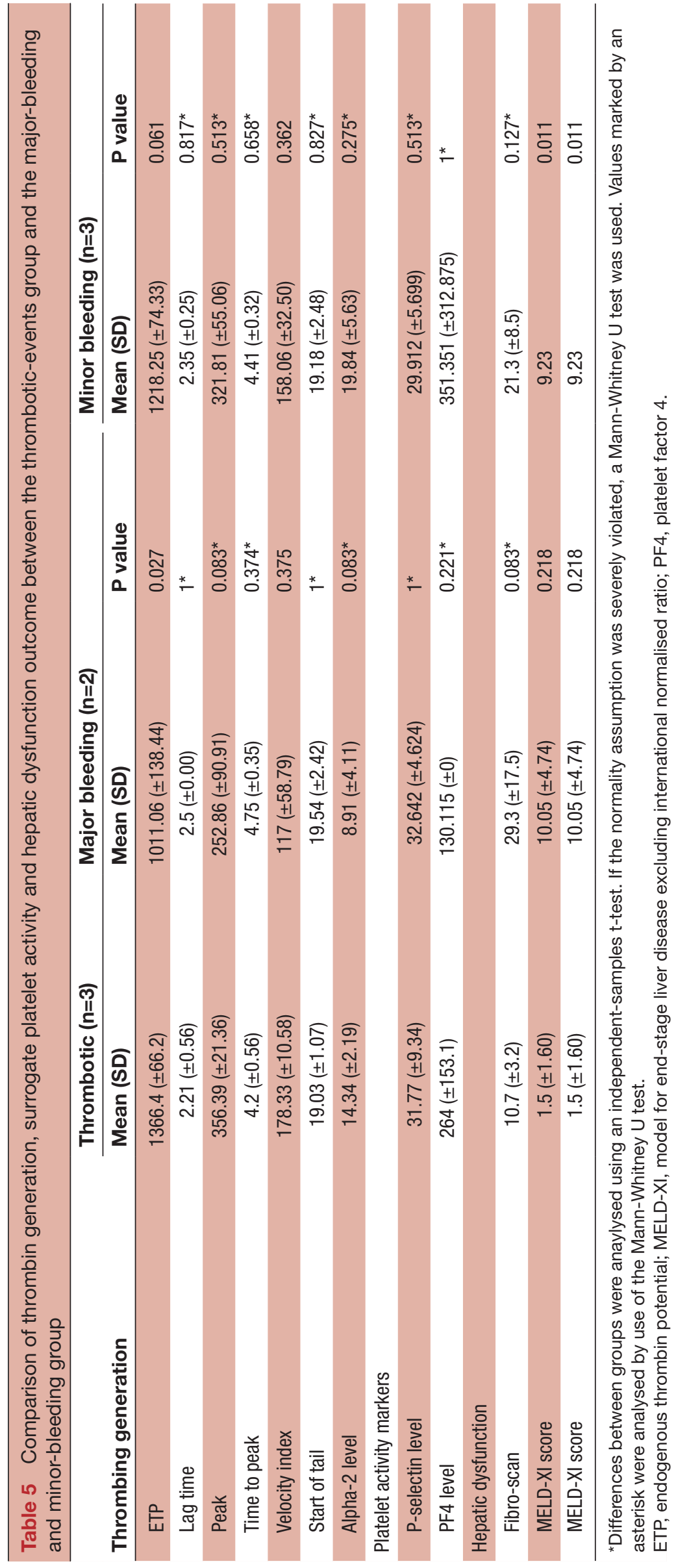




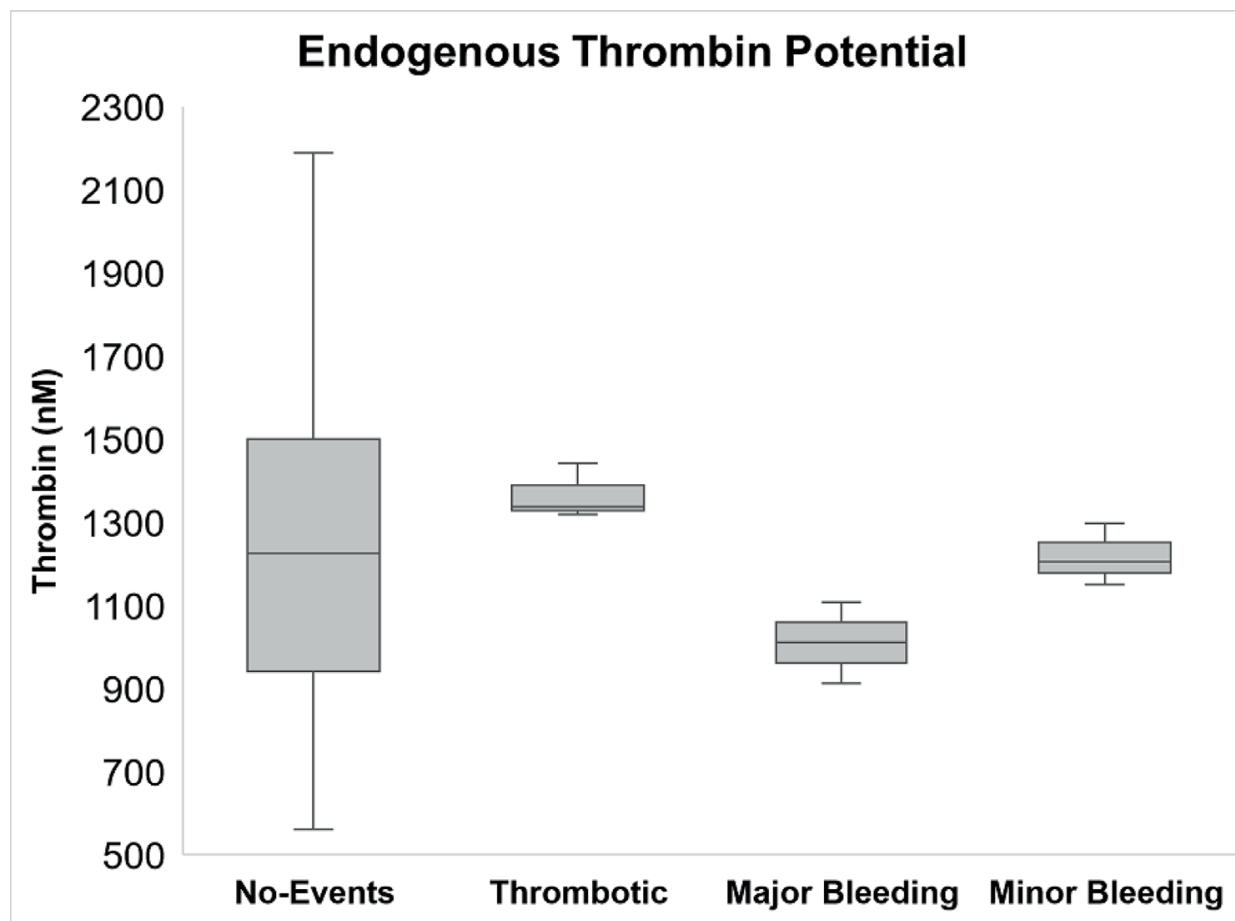

Figure 2 Distribution of endogenous thrombin potential between the different subgroups.

\section{Hepatic dysfunction}

The results of the correlation analyses between markers for hepatic dysfunction and TG and surrogate platelet activity are reported in table 7 .

There was a weak positive correlation between the MELD-XI score and the start of the tail of the TG curve, $\tau=0.17, p=0.045$. There was a weak positive correlation between MELD-XI score and time to peak, $\tau=0.207$, $\mathrm{p}=0.013$. The platelet activity markers and the remaining TG variables did not correlate with MELD-XI scores.

There was a weak negative correlation between the Fibrotest score and PF4, $\tau=-0.20, p=0.046$. Other surrogate markers for platelet activity and $\mathrm{TG}$ variables did not correlate with Fibrotest score.

Table 6 Comparison of thrombin generation-, surrogate platelet activity and hepatic dysfunction outcome between the major-bleeding and minor-bleeding group

\begin{tabular}{lccc}
\hline & Major bleeding & Minor bleeding & P value \\
\cline { 2 - 2 } Thrombing generation & Mean (SD) & Mean (SD) & 0.109 \\
\hline ETP & $1011.06( \pm 138.44)$ & $1218.25( \pm 74.33)$ & $0.248^{\star}$ \\
\hline Peak & $252.86( \pm 90.91)$ & $321.81( \pm 55.06)$ & $0.374^{\star}$ \\
\hline Time to peak & $4.75( \pm 0.35)$ & $158.06( \pm 0.32)$ & 0.373 \\
\hline Velocity index & $117.00( \pm 58.79)$ & $19.84( \pm 5.63)$ & $0.083^{\star}$ \\
\hline Alpha-2 level & $8.91( \pm 4.11)$ & & $0.564^{\star}$ \\
\hline Platelet activity markers & & $29.912( \pm 5.699)$ & $0.48^{\star}$ \\
\hline P-selectin level & $32.642( \pm 4.624)$ & $351.351( \pm 312.875)$ & \\
\hline PF4 level & $130.115( \pm 0)$ & & $0.564^{\star}$ \\
\hline Hepatic dysfunction & $29.3( \pm 17.5)$ & $0.692( \pm 0.24)$ & 0.587 \\
\hline Fibro-scan & $0.471( \pm 0)$ & $9.23( \pm 2.52)$ & 0.811 \\
\hline Fibro-test score & $10.05( \pm 4.74)$ & & \\
\hline MELD-XI score &
\end{tabular}

*Differences between groups were anaylysed using an independent-samples t-test. If the normality assumption was severely violated, a Mann-Whitney $U$ test was used. Values marked by an asterisk were analysed by use of the Mann-Whitney $U$ test.

ETP, endogenous thrombin potential; MELD-XI, model for end-stage liver disease excluding international normalised ratio; PF4, platelet factor 4 . 


\begin{tabular}{|c|c|c|c|c|c|c|c|c|c|c|}
\hline & & ETP & Lag time & Peak & $\begin{array}{l}\text { Time to } \\
\text { peak }\end{array}$ & $\begin{array}{l}\text { Velocity } \\
\text { index }\end{array}$ & $\begin{array}{l}\text { Start of } \\
\text { tail }\end{array}$ & $\begin{array}{l}\text { Alpha-2 } \\
\text { level }\end{array}$ & $\begin{array}{l}\text { P-selectin } \\
\text { level }\end{array}$ & PF4 level \\
\hline \multirow[t]{2}{*}{ MELD-XI score } & Correlation & 0.073 & 0.131 & 0.023 & $0.198^{*}$ & -0.051 & $0.171^{*}$ & -0.065 & -0.088 & -0.127 \\
\hline & $P$ value & 0.540 & 0.142 & 0.786 & 0.025 & 0.669 & 0.045 & 0.441 & 0.308 & 0.189 \\
\hline \multirow[t]{2}{*}{ Median KPA } & Correlation & -0.138 & 0.125 & $-0.174^{*}$ & 0.124 & $-0.177^{*}$ & 0.127 & -0.155 & -0.010 & -0.055 \\
\hline & $P$ value & 0.101 & 0.160 & 0.038 & 0.154 & 0.035 & 0.131 & 0.065 & 0.907 & 0.576 \\
\hline \multirow[t]{2}{*}{ Fibrotest score } & Correlation & -0.174 & 0.090 & -0.108 & 0.156 & -0.218 & 0.154 & 0.083 & -0.094 & $-0.201^{*}$ \\
\hline & $P$ value & 0.188 & 0.340 & 0.226 & 0.093 & 0.097 & 0.087 & 0.353 & 0.298 & 0.046 \\
\hline
\end{tabular}

*Correlations between variables were analysed using a Pearson's $r$. If the normality assumption of either variable was violated, a Kendall's tau coefficient was used to analyse correlations between variables. Values marked by an asterisk were analysed by use of the Kendall's tau coefficient.

ETP, endogenous thrombin potential; MELD-XI, model for end-stage liver disease excluding international normalised ratio; PF4, platelet factor 4 .

\section{DISCUSSION}

An increased ETP was found in the thrombotic group compared with the major-bleeding group and the thrombotic group showed a trend for a higher ETP compared with the minor bleeding group. An increased ETP has been correlated to a more coagulable state which is associated with an increased risk of TE. ${ }^{21}$ The mean ETP of the no-events group was not statistically different from the thrombotic- and the major-bleeding group which might be due to the small sample sizes. The mean ETP of the no-events group did, however, lie between the mean values of the thrombotic and bleeding groups. This limits the use of TG as a predictive test for haemostatic complications but shows potential for its use in the early detection of haemostatic derangements and stratification of anticoagulant therapy.

The height of peak showed a trend for a higher peak in the thrombotic group which lead to a more hypercoagulable state. The height of peak shows the highest amount of active thrombin at a certain time. A lower peak is associated with a more bleeding like diathesis. ${ }^{22}$ When compared with the no events group, the thrombotic group has a higher velocity index while no significant difference was observed between the thrombotic group and the bleeding groups. There was a trend for a higher $\alpha 2 \mathrm{M}$ level in the minor bleeding group compared with the no-events group and a trend for a lower $\alpha 2 \mathrm{M}$ level in the major bleeding group compared with the thrombotic group. $\alpha 2 \mathrm{M}$ functions as an inhibitor of fibrinolysis and thrombin but the direction of effect of the observed $\alpha 2 \mathrm{M}$ levels on thrombus formation is however unclear. ${ }^{23}$ A higher velocity index reflects the speed at which prothrombin is converted to thrombin. ${ }^{21}$ It is possible that the higher velocity index in the thrombotic group is the reason these patients are more likely to develop thrombosis.

An inverse correlation was observed between MELD-XI score and time to peak and the start of the tail of the TG curve. The start of the tail is the moment at which there is no free thrombin and that at which thrombin only exists as $\alpha 2 \mathrm{M}$-thrombin complex. ${ }^{14}$ Our finding, therefore, suggests that hepatic dysfunction might lead to a longer time to peak, which could be explained by the derangement in procoagulant and anticoagulant factors which has been reported within this patient population. A longer time to peak is however associated with a bleeding like phenotype. A later start of the TG curve tail might be explained by a longer time to peak but could also be explained by a slower inactivation of free thrombin by $\alpha 2 \mathrm{M}$. This would allow thrombin to be active for a longer time and could thereby lead to a more thrombotic-like diathesis.

The observed differences in MELD-XI scores between subgroups might have arisen due to differences in prevalence of different Fontan types since Fontan types were not evenly distributed between the different subgroups. Concerns about which modality to use to determine liver dysfunction in $\mathrm{CH}$, as seen in Fontan patients, have been raised. ${ }^{18}$ Current clinical tools as serum tests, imaging studies, liver stiffness measurements and liver biopsy failed to accurately estimate hepatic fibrosis or the risk for hepatic decompensation in Fontan patients. Wilson et al published data demonstrating changes in several different non-invasive markers of liver and renal damage in Fontan patients but also acknowledges the limits of using such modalities in this population. ${ }^{18}$ Even liver biopsy, considered the golden standard to assess fibrosis staging, has little predictive value due to the heterogeneous collagen depositions observed in CH. Conjointly, liver biopsy carries a significant bleeding risk and is therefore seldomly performed. At this moment, the MELD-XI score is the only validated modality to assess hepatic dysfunction and predict clinical outcome in $\mathrm{CH}$ but its correlation to clinical outcome is moderate at best making it far from the perfect method to study liver fibrosis in this population. ${ }^{1}$ Staging hepatic dysfunction in this patient group remains challenging and highlights the need for care in data interpretation. Prescribing anticoagulants to Fontan patients is elaborate considering the disturbances in the haemostatic system and the far-reaching consequences of both bleeding and TE. Scientific Statements from the American Heart Association, American College 
of Chest Physician Guidelines and European Society of Cardiology Guidelines on the management of grown-up congenital heart disease state that thromboprophylaxis post-Fontan surgery is appropriate considering the high risk of thrombosis associated morbidity and mortality. ${ }^{24-26}$ Current evidence for the optimal antithrombotic therapy and duration for Fontan patients is limited. ${ }^{27}$ Importantly, bleeding complications do occur in Fontan patients and that risk is increased by antithrombotic therapy. ${ }^{2}$ These results show potential for the clinical application of TG as modality to stratify anticoagulant therapy for post-Fontan patients.

\section{Limitations}

This study is limited by the inherent design of observational research and the noted shortfalls of doing research in this specific population. In pointing out the limitations of this study, we acknowledge that some of the reported trends might have arisen as statistical consequence of the small sample sizes within various subgroups and should therefore be interpreted with caution.

\section{CONCLUSIONS}

This is the first large study to investigate the haemostatic profile in Fontan patients with hepatic dysfunction and to correlate their haemostatic profiles to bleeding and TE. We found that ETP is associated with TE and majorbleeding events during clinical follow-up after Fontan palliation. This study underlines the importance of taking a broader approach to haemostasis in patients with a Fontan circulation and hepatic dysfunction, as their physiology greatly affects most factors within the haemostatic system.

\section{Author affiliations \\ ${ }^{1}$ Cardiology, University Medical Centre Amsterdam, Amsterdam, Netherlands ${ }^{2}$ Heamatology Research, Murdoch Childrens Research Institute, Melbourne, Victoria, Australia \\ ${ }^{3}$ Paediatric Cardiology, Wilhelmina Children's Hospital, University Medical Centre Utrecht, Utrecht, Netherlands \\ ${ }^{4}$ Heart Research, Murdoch Childrens Research Institute, Melbourne, Victoria, Australia \\ ${ }^{5}$ Paediatrics, Murdoch Childrens Research Institute, Melbourne, Victoria, Australia ${ }^{6}$ Faculty of Medicine, University of Melbourne, Melbourne, Victoria, Australia ${ }^{7}$ Heart Centre for Children, The Children's Hospital at Westmead, Sydney, New South Wales, Australia \\ ${ }^{8}$ Cardiothoracic Surgery, St Vincent's Hospital, Sydney, New South Wales, Australia ${ }^{9}$ Paediatric and Congenital Cardiology, Starship Childrens Hospital, Auckland, New Zealand \\ ${ }^{10}$ Paediatrics and Clinical Hematology, The Royal Children's Hospital Melbourne, Melbourne, Victoria, Australia}

\section{Twitter David Winlaw @drwinlaw}

Acknowledgements The authors acknowledge support provided to the Murdoch Children's Research Institute by the Victorian Government's Operational Infrastructure Support Programme. Yves d'Udekem is a NHMRC Clinician Practitioner Fellow (1082186).

Contributors JJND: primary investigator. CA: study coordinator, manuscript review. SVDH: ELISA testing. JB: manuscript planning and review. YD: principal investigator.
KdP: Fontan Registry employee. TGW: data retrieval and collation, manuscript review. DW: patient recruitment, registry management, clinical review, manuscript review. PM: secondary study supervisor. Vl: primary supervisor.

Funding This project was supported by a grant from the National Health and Medical Research Council (NHMRC Project Grant 1047923).

Competing interests YD is consultant for MSD and Actelion. The remaining authors have no conflicts of interest to declare.

Patient consent for publication Not required.

Ethics approval The full design of the present study has been approved by the national and local ethics committees of all participating hospitals.

Provenance and peer review Not commissioned; externally peer reviewed.

Data availability statement Data are available on reasonable request. All data relevant to the study are included in the article or uploaded as online supplemental information. Data consists of deidentified participant data from the Australian and New Zealand Fontan registry and was registered with consent and within ethical approval within the Fontan Liver Renal study (doi:10.1016/j.ijcard.2018.07.118). Data can be requested by contacting professor VI on verai@unimelb.edu.au.

Open access This is an open access article distributed in accordance with the Creative Commons Attribution Non Commercial (CC BY-NC 4.0) license, which permits others to distribute, remix, adapt, build upon this work non-commercially, and license their derivative works on different terms, provided the original work is properly cited, appropriate credit is given, any changes made indicated, and the use is non-commercial. See: http://creativecommons.org/licenses/by-nc/4.0/.

\section{ORCID iDs}

Joelle Julius Nicolaas Daems http://orcid.org/0000-0002-5589-2806

David Winlaw http://orcid.org/0000-0001-8005-3361

\section{REFERENCES}

1 Lemmer A, VanWagner LB, Ganger D. Assessment of advanced liver fibrosis and the risk for hepatic decompensation in patients with congestive hepatopathy. Hepatology 2018;68:1633-41.

2 Alsaied T, Bokma JP, Engel ME, et al. Factors associated with longterm mortality after Fontan procedures: a systematic review. Heart 2017;103:104-10.

3 Alsaied T, Alsidawi S, Allen CC, et al. Strategies for thromboprophylaxis in Fontan circulation: a meta-analysis. Heart 2015;101:1731-7.

4 Fontan F, Baudet E. Surgical repair of tricuspid atresia. Thorax 1971;26:240-8.

5 Firdouse M, Agarwal A, Chan AK, et al. Thrombosis and thromboembolic complications in Fontan patients: a literature review. Clin Appl Thromb Hemost 2014;20:484-92.

6 Tomkiewicz-Pajak L, Hoffman P, Trojnarska O, et al. Abnormalities in blood coagulation, fibrinolysis, and platelet activation in adult patients after the Fontan procedure. $J$ Thorac Cardiovasc Surg 2014;147:1284-90.

7 Monagle P, Karl TR. Thromboembolic problems after the Fontan operation. Semin Thorac Cardiovasc Surg Pediatr Card Surg Annu 2002;5:36-47.

8 Gewillig M, Brown SC. The Fontan circulation after 45 years: update in physiology. Heart 2016;102:1081-6.

9 Dahlbäck B. Blood coagulation. The Lancet 2000;355:1627-32.

10 Lisman T, Porte RJ. Rebalanced hemostasis in patients with liver disease: evidence and clinical consequences. Blood 2010;116:878-85.

11 Magnusson M, Ignjatovic V, Hardikar W, et al. A conceptual and practical approach to haemostasis in paediatric liver disease. Arch Dis Child 2016;101:854-9.

12 Asrani SK, Warnes CA, Kamath PS. Hepatocellular carcinoma after the Fontan procedure. N Engl J Med 2013;368:1756-7.

13 Hemker HC, Giesen P, AlDieri R, et al. The calibrated automated thrombogram (cat): a universal routine test for hyper- and hypocoagulability. Pathophysiol Haemost Thromb 2002;32:249-53.

14 Hemker HC. Thrombin generation: biochemical possibilities and clinical reality. Blood 2015;126:288-9.

15 Hemker HC, Giesen P, Al Dieri R, et al. Calibrated automated thrombin generation measurement in clotting plasma. Pathophysiol Haemost Thromb 2003;33:4-15.

16 Kremers RMW, Peters TC, Wagenvoord RJ, et al. The balance of pro- and anticoagulant processes underlying thrombin generation. $J$ Thromb Haemost 2015;13:437-47. 
17 lyengar AJ, Winlaw DS, Galati JC, et al. The Australia and New Zealand Fontan registry: description and initial results from the first population-based Fontan registry. Intern Med J 2014;44:148-55.

18 Wilson TG, d'Udekem Y, Winlaw DS, et al. Hepatic and renal endorgan damage in the Fontan circulation: a report from the Australian and New Zealand Fontan registry. Int J Cardiol 2018;273:100-7.

19 Assenza GE, Graham DA, Landzberg MJ, et al. MELD-XI score and cardiac mortality or transplantation in patients after Fontan surgery. Heart 2013;99:491-6.

20 Schulman S, Kearon C. The Subcommittee on control of anticoagulation of the scientific and standardization Committee of the International Society on thrombosis and haemostasis. Definition of major bleeding in clinical investigations of antihemostatic medicinal products in non-surgical patients. Journal of Thrombosis and Haemostasis 2005;3:692-4.

21 Tripodi A, Legnani C, Chantarangkul V, et al. High thrombin generation measured in the presence of thrombomodulin is associated with an increased risk of recurrent venous thromboembolism. J Thromb Haemost 2008;6:1327-33.

22 Castoldi E, Rosing J. Thrombin generation tests. Thromb Res 2011;127 Suppl 3:S21-5.
23 de Boer JP, Creasey AA, Chang A, et al. Alpha-2-Macroglobulin functions as an inhibitor of fibrinolytic, clotting, and neutrophilic proteinases in sepsis: studies using a baboon model. Infect Immun 1993;61:5035-43.

24 Guyatt GH, Akl EA, Crowther M, et al. Executive summary: antithrombotic therapy and prevention of thrombosis, 9th ED: American College of chest physicians evidence-based clinical practice guidelines. Chest 2012;141:7S-47.

25 Baumgartner H, Bonhoeffer P, De Groot NMS, et al. ESC guidelines for the management of grown-up congenital heart disease (new version 2010): the task force on the management of grown-up congenital heart disease of the European Society of cardiology (ESC). Eur Heart J 2010;31:2915-57.

26 Giglia TM, Massicotte MP, Tweddell JS, et al. Prevention and treatment of thrombosis in pediatric and congenital heart disease: a scientific statement from the American heart association. Circulation 2013;128:2622-703.

27 Attard C, Huang J, Monagle P, et al. Pathophysiology of thrombosis and anticoagulation post Fontan surgery. Thromb Res 2018;172:204-13. 